\title{
Erratum to: Genomic differences in benign and malignant follicular thyroid tumours using 1-Mb array-comparative genomic hybridisation
}

\author{
Abdul A. Qureshi · V. P. Collins · P. Jani
}

Published online: 7 December 2012

(c) Springer-Verlag Berlin Heidelberg 2012

Erratum to: Eur Arch Otorhinolaryngol

DOI 10.1007/s00405-012-2017-4

Unfortunately, the labeling of Figs. 7 and 8 was inadvertently removed in the online published article. The complete Figs. 7 and 8 are given below.

The online version of the original article can be found under doi:10.1007/s00405-012-2017-4.

A. A. Qureshi · P. Jani

Department of Otolaryngology, Addenbrooke's Hospital,

Hills Road, Cambridge CB2 OQQ, UK

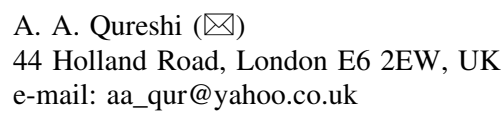

Department of Molecular Histopathology, Addenbrooke's Hospital, Hills Road, Cambridge CB2 0QQ, UK 


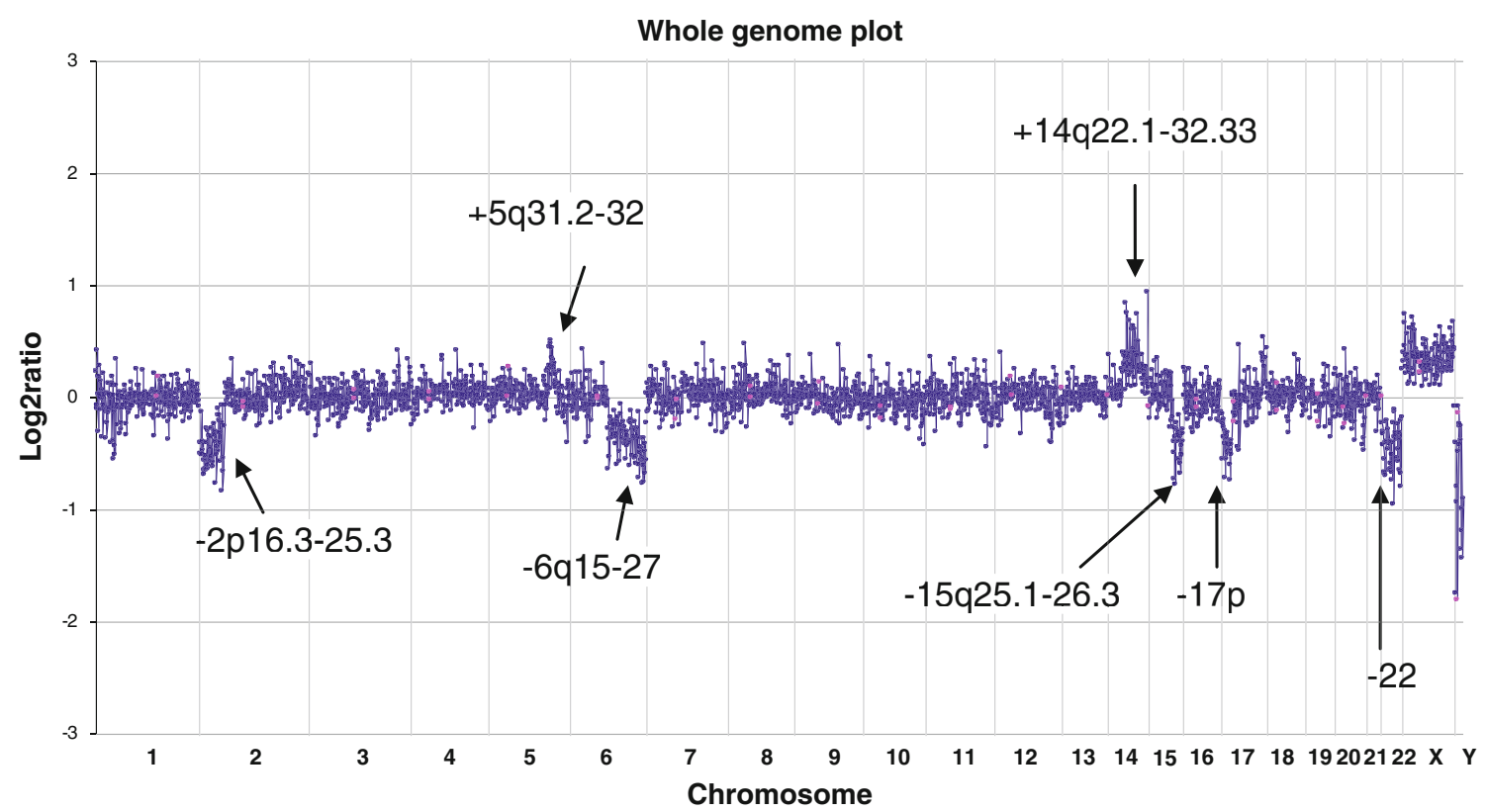

Fig. 7 De-differentiating follicular thyroid cancer-identifiable changes are marked

Fig. 8 A potential Vogelgram for follicular thyroid tumourigenesis (adopted from Table 2)

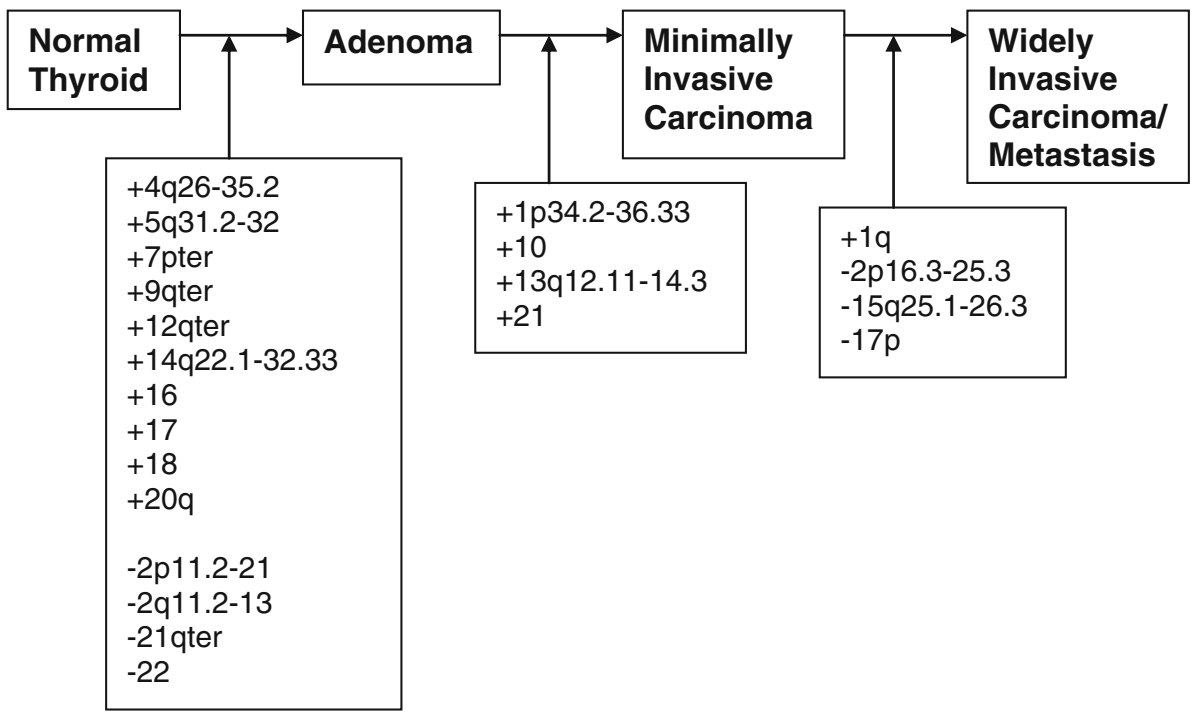

